\title{
Non-invasive pregnancy diagnosis from urine by the Cuboni reaction and the barium chloride test in donkeys (Equus asinus) and alpacas (Vicugna pacos)
}

\author{
A. Kubátová, T. Fedorova, I. Skálová, L. Hyniová \\ Department of Animal Science and Food Processing, Faculty of Tropical AgriSciences, \\ Czech University of Life Sciences Prague, Kamýcká 129, 16521 Prague 6, Czech Republic
}

\begin{abstract}
The aim of the research was to evaluate two chemical tests for non-invasive pregnancy diagnosis from urine, the Cuboni reaction and the barium chloride test, in donkeys (Equus asinus) and alpacas (Vicugna pacos). The research was carried out from April 2013 to September 2014. Urine samples were collected on five private Czech farms from 18 jennies and 12 alpaca females. Urine was collected non-invasively into plastic cups fastened on a telescopic rod, at 6-9 week intervals. In total, 60 and 54 urine samples from alpacas and jennies, respectively, were collected. The Cuboni reaction was performed by the State Veterinary Institute Prague. The barium chloride test was done with $5 \mathrm{ml}$ of urine mixed together with $5 \mathrm{ml}$ of $1 \%$ barium chloride solution. Results of the Cuboni reaction were strongly influenced by the reproductive status of jennies; the test was $100 \%$ successful throughout the second half of pregnancy. However, no relationship was found between the real reproductive status of alpaca females and results of the Cuboni reaction. It was concluded that the barium chloride test is not suitable for pregnancy diagnosis either in donkeys, due to significant influence of season on the results, or in alpacas, because no relationship between results of the test and the reproductive status of alpaca females was found. In conclusion, the Cuboni reaction has potential to become a standard pregnancy diagnostic method in donkeys.
\end{abstract}

Key words: chemical test, jennies, non-invasive, spontaneous urination, urine collection

\section{Introduction}

Pregnancy diagnosis is essential for better reproductive management in captive animals (Thomas et al. 2010). Urine sampling by free catch is a non-invasive research method (Cote 2014) that enables collection of urine without restraining or capturing animals (Waits and Paetkau 2005), and breeders can collect urine by themselves. Pregnancy diagnosis from urine can be done by hormone analysis of the urine, but these methods mostly require collection of multiple samples and laboratory testing which are not always

Correspondence to: T. Fedorova, e-mail: fedorova@ftz.czu.cz 
available (Hodges et al. 2010). Moreover, results of these analyses are available with some delay (Simersky et al. 2007).

Donkeys (Equus asinus) and alpacas (Vicugna pacos) are important husbandry animals for certain regions (FAO 2015). Moreover, both species are also bred as hobby animals in Europe, Australia, USA and other countries (Webster 2011) and although they are not closely related species, there are some similarities in their reproduction. The oestrous cycle in donkey jennies is influenced by season (Blanchard et al. 1999); however, according to Contri et al. (2014), not as strongly as in horse mares. In jennies, oestrous can be present during whole year in Europe. Alpaca females also show reproductive seasonality in the Andean region but they act like non-seasonal breeders in conditions of the Northern Hemisphere (Sumar 1999). Adult alpaca females do not show a typical oestrous cycle. Instead, they have continuous oestrous with short periods of non-receptivity (Fernández-Baca 1993), and ovulation is induced by mating (Bravo et al. 1991, Gauly and Bourke 1997). A relatively long gestation is typical for both species. The mean length of gestation is 365 days in donkeys (McDonnell 1998, Galisteo and Perez-Marin 2010) and about 345 days in alpacas (Volkery et al. 2012).

Various methods of pregnancy diagnosis are known in donkeys and alpacas but many of them are invasive, e.g. trans-rectal palpation (Rota et al. 2012, You et al. 2013) or measurement of hormonal levels in blood (Volkery et al. 2010, Crisci et al. 2014). Trans-abdominal ultrasonography (TAU) and male teasing are the most common non-invasive methods of pregnancy diagnosis in donkeys (Crisci et al. 2014) and alpacas (Volkery et al. 2010). However, an experienced sonographer (Rizk 2010) and relatively expensive equipment (Ndu et al. 2000a) are needed for TAU. Besides this, the method is time-consuming and requires clipping of a large portion of hair (Anderson et al. 2013). In the case of male teasing, the diagnosis can be done by breeders themselves but it is dependent on owning male individuals.

Because of this, there is a need for reliable, simple, affordable and non-invasive pregnancy diagnostic methods for alpacas and donkeys. For horse mares (Equus caballus) and donkeys, on-farm kits like the Wee-Foal-Checker exist, which are based on detection of a pregnancy-associated oestrogenic steroid metabolite in urine (Purohit 2010). Use of commercial urinary kits for donkeys is not always possible because of market inaccessibility in some countries and the relatively high price for one test. Nevertheless, other pregnancy tests from urine exist, such as chemical tests like the Cuboni reaction (Cuboni 1934) and the barium chloride test (Maslov and Smirnov 1965).
Both are probably based on the reaction of oestrogens with chemical substances (Stevenson 1945, Maslov and Smirnov 1965).

According to the authors' information, there is no available data on urinary oestrogen levels in jennies. However, blood levels are available. Concentrations of total oestrone remain $<1 \mathrm{ng} / \mathrm{ml}$ until the sixth week of pregnancy, then they increase to $600-2700 \mathrm{ng} / \mathrm{ml}$ during midpregnancy and again decrease to $1-20$ $\mathrm{ng} / \mathrm{ml}$ during the last two weeks of pregnancy (Hoffmann et al. 2014).

Concerning urinary oestrogen levels in alpacas, oestrone sulphate (E1S) concentration peaks twice during pregnancy. According to Bravo et al. (1996), the first peak is reached 21 days after mating, but the possibility of diagnosing pregnancy by the first peak of E1S was doubted by Volkery et al. (2012). The second peak is reached during the last month of gestation (Bravo et al. 1996, Volkery et al. 2012), when E1S concentrations reach $104.03 \pm 24.09 \mathrm{ng}$ E1S/mg creatinine. During the rest of the pregnancy, the average level is $8.82 \pm 1.40 \mathrm{ng}$ E1S/mg creatinine, which is very similar to the level in non-pregnant females (6.14 $\pm 0.53 \mathrm{ng}$ E1S/mg creatinine) (Volkery et al. 2012).

The Cuboni reaction, which was developed for pregnancy diagnosis in horse mares (Cuboni 1934), is a test based on the colour reaction of free oestrogens in urine with sulphuric acid $\left(\mathrm{H}_{2} \mathrm{SO}_{4}\right)$. In the urine of pregnant females, green opalescence should be detected after the Cuboni reaction. In the urine of non-pregnant females, a brown-red colouring should be visible (Stevenson 1945). According to Hayes (2002), it is possible to detect pregnancy in mares by the Cuboni reaction from 120 days after the conception. To get reliable results, it is better to wait until the $150^{\text {th }}$ day of pregnancy, i.e. to the time of peak concentration of placental oestrogens in plasma and urine, or even later, when the concentrations are still high, approximately up to the $300^{\text {th }}$ day of pregnancy (England 2008). The Cuboni reaction has not been tested either in other Equus species or in South American camelids (Lama sp. or Vicugna sp.) but it has already been used in camels which are closely related to alpacas (Groves and Grubb 2011). In Bactrian camels (Camelus bactrianus) the Cuboni reaction was successful in the final third of pregnancy, when accuracy was $100 \%$ (Fedorova et al. 2015). In Arabian camels (Camelus dromedarius), sure positive reactions were obtained from slaughtered females with foetuses that had a crown vertebral rump length in the range 60-120 cm (El-Ghannam et al. 1974), which is reached during the second third of pregnancy (Bello et al. 2014).

The barium chloride test was developed by Maslov and Smirnov (1965), who discovered that addition of 
a $1 \%$ solution of barium chloride $\left(\mathrm{BaCl}_{2}\right)$ to urine of non-pregnant cows (Bos taurus) causes creation of a white precipitate. In contrast, there is no reaction after addition of $1 \% \mathrm{BaCl}_{2}$ to the urine of pregnant cows. Even though the test is 50 years old, the factors preventing or inducing precipitation have not yet been discovered (Ndu et al. 2000a, Ndu et al. 2000b, Lalrintluanga and Dutta 2009). Oestrogens and progesterone are suspected as factors that can prevent precipitation (Maslov and Smirnov 1965, Lalrintluanga and Dutta 2009), but there are also researchers who do not agree (Ndu et al. 2000a,b). Lalrintluanga and Dutta (2009) reported the examination of this test in mares, but the results are not known. In Bactrian camels, the potency of the barium chloride test was not confirmed (Fedorova et al. 2015). However, according to Banerjee (1974), reliability was $85 \%$ between $50^{\text {th }}$ and $90^{\text {th }}$ day of pregnancy in Arabian camels (Purohit 2010).

The aim of this research was to evaluate the barium chloride test and the Cuboni reaction as pregnancy diagnostic tests for possible use in alpacas and donkeys.

\section{Materials and Methods}

Animals

Urine was collected from 18 jennies (Equus asinus) from two private Czech farms and from 12 alpaca females (Vicugna pacos) of huacaya type from three other private Czech farms. All alpaca females and 16 of the jennies were in their reproductive period; two jennies were still foals. The date of parturition was recorded for each pregnancy, and the sampling period in females was expressed as the number of days before parturition. Moreover, the date of the last successful mating as the day of probable conception was obtained from the breeders in the case of 11 pregnancies in donkeys and four pregnancies in alpacas and so the length of pregnancy was also calculated. An abortion occurred in one alpaca female during the study period and the date of parturition was estimated by a veterinarian according to the development of the foetus.

\section{Urine sampling and processing}

Urine samples were collected repeatedly from pregnant and non-pregnant animals at 6-9 week intervals from April 2013 to September 2014 and, in total, there were from one to five samplings from each jenny and five samplings from each alpaca female. The sampling period was from 34 to 363 and from 22 to 343 days before parturition in pregnant jennies and pregnant alpaca females, respectively. Non-pregnant animals were sampled repeatedly during different parts of the year. Urine was caught during spontaneous urination of the animals in half-litre plastic cups that were fastened onto a telescopic rod (Fedorova et al. 2015) or held in the hand in the case of tamed animals. Collected urine was poured into plastic test tubes $(20 \mathrm{ml}$ volume) for the purpose of transport and storage. Samples were refrigerated (Fedorova et al. 2015) at 5-7 ${ }^{\circ} \mathrm{C}$ until testing. Before testing, urine was kept outside the refrigerator to reach room temperature and was then homogenised.

\section{Cuboni reaction}

Samples for the Cuboni reaction were transported to the State Veterinary Institute (SVI) Prague within one week after sampling and the reaction was done there by the method standardised for horse mares. The procedure of the Cuboni reaction in the SVI Prague was following: Urine was filtrated through filter paper and $5 \mathrm{ml}$ of filtrated urine was mixed with $1 \mathrm{ml}$ of concentrated hydrochloric acid $(\mathrm{HCl})$ in a test tube. Then, the test tube was put into a boiling water bath for $10 \mathrm{~min}$. After cooling, $6 \mathrm{ml}$ of toluene was added and the solution was stirred properly. After $1 \mathrm{~min}$, the two layers of the solution were divided. The lower layer with toluene was separated and filtrated into a clear test tube containing $1 \mathrm{ml}$ of concentrated $\mathrm{H}_{2} \mathrm{SO}_{4}$. The mixture was stirred properly again and put into an $80^{\circ} \mathrm{C}$ water bath for approximately $15 \mathrm{~min}$. After cooling, the colour of opalescence in the test tube placed on a dark background was evaluated.

\section{Barium chloride test}

Barium chloride tests were carried out in the laboratory of the Department of Animal Science and Food Processing, Czech University of Life Sciences Prague (CULS Prague) within one week after collection. In a test tube, $5 \mathrm{ml}$ of urine was mixed with $5 \mathrm{ml}$ of a $1 \% \mathrm{BaCl}_{2}$ solution (Krishna Rao and Veena 2009, Lalrintluanga and Dutta 2009). Then, the solution was agitated and left to stand for $5 \mathrm{~min}$ ( $\mathrm{Ndu}$ et al. 2000a,b); after this, results were evaluated. Samples which showed any degree of cloudiness or turbidity after 5 min were regarded as having shown precipitation with the reagent and the test was concluded as negative (animal should be non-pregnant). When no reaction occurred in $5 \mathrm{~min}$, the test was concluded as positive (animal should be pregnant) (Ndu et al. 2000a,b). 
Table 1. Results of the Cuboni reaction in non-pregnant and pregnant jennies in the first and second halves of pregnancy. The results were significantly affected by the reproductive status $(\mathrm{p}<0.01)$.

\begin{tabular}{lccc}
\hline \multirow{2}{*}{ Result of the Cuboni reaction } & \multicolumn{3}{c}{ Reproductive status of females } \\
\cline { 2 - 4 } & $\begin{array}{c}\text { Non-pregnant } \\
(\mathrm{n}=23)\end{array}$ & $\begin{array}{c}1 / 2 \text { pregnancy } \\
(\mathrm{n}=14)\end{array}$ & $\begin{array}{c}2 / 2 \text { pregnancy } \\
(\mathrm{n}=17)\end{array}$ \\
\hline Positive & $13.04 \%$ & $64.29 \%^{*}$ & $100.00 \%^{*}$ \\
\hline Negative & $86.96 \%^{*}$ & $35.71 \%$ & $0.00 \%$ \\
\hline
\end{tabular}

* An asterisk marks the correct results of the test (the result of the test correspond with the reproductive status of female).

Table 2. Results of the Cuboni reaction in non-pregnant and pregnant jennies in the first, second and final thirds of pregnancy. The results were significantly affected by the reproductive status $(\mathrm{p}<0.01)$.

\begin{tabular}{lcccc}
\hline \multirow{2}{*}{ Result of the Cuboni reaction } & \multicolumn{4}{c}{ Reproductive status of females } \\
\cline { 2 - 5 } & $\begin{array}{c}\text { Non-pregnant } \\
(\mathrm{n}=23)\end{array}$ & $\begin{array}{c}1 / 3 \text { pregnancy } \\
(\mathrm{n}=13)\end{array}$ & $\begin{array}{c}2 / 3 \text { pregnancy } \\
(\mathrm{n}=13)\end{array}$ & $\begin{array}{c}3 / 3 \text { pregnancy } \\
(\mathrm{n}=10)\end{array}$ \\
\hline Positive & $13.04 \%$ & $50.00 \% \%^{*}$ & $92.31 \%^{*}$ & $100.00 \%^{*}$ \\
\hline Negative & $86.96 \% *$ & $50.00 \%$ & $7.69 \%$ & $0.00 \%$ \\
\hline
\end{tabular}

* An asterisk marks the correct results of the test (the result of the test correspond with the reproductive status of female).

Table 3. Results of the Cuboni reaction in non-pregnant and pregnant alpaca females. The results were not significantly affected by the reproductive status $(\mathrm{p}>0.05)$.

\begin{tabular}{lcc}
\hline \multirow{2}{*}{\begin{tabular}{c} 
Result of the Cuboni reaction \\
\cline { 2 - 3 }
\end{tabular}} & $\begin{array}{c}\text { Ron-pregnant } \\
(\mathrm{n}=30)\end{array}$ & $\begin{array}{c}\text { Pregnant } \\
(\mathrm{n}=28)\end{array}$ \\
\hline Positive & $73.33 \%$ & $64.29 \%^{*}$ \\
\hline Negative & $26.67 \%^{*}$ & $35.71 \%$ \\
\hline
\end{tabular}

* An asterisk marks the correct results of the test (the result of the test correspond with the reproductive status of female).

\section{Statistical analysis}

In cases where the last mating date was unknown, 365 and 345 days were considered as the mean lengths of pregnancy in donkeys (McDonnell 1998, Galisteo and Perez-Marin 2010) and alpacas (Volkery et al. 2012), respectively. Samples that were collected earlier than 365 and 345 days before parturition in jennies and alpacas, respectively, were considered as samples from a period of non-pregnancy. Postmature birth occurred in one alpaca female so the length of gestation of this female was not included in the general analysis.

The accuracy of the barium chloride test and Cuboni reaction were determined by comparison of the results with the real reproductive status of females which was either pregnant or non-pregnant. The results of the tests, which correspond with the reproductive status of females, were assessed as the correct results. Other results were evaluated as false-positive or false-negative. However, the reliability of individual tests in pregnant females was counted not only for the whole pregnancy period, but also for its halves and thirds. In alpacas, the analysis was also divided into the first month (first 31 days) of pregnancy, middle part (from 32 to 314 days) of pregnancy and the last month (last 31 days) of pregnancy. Additionally, the first 314 days and last month (31 days) of pregnancy were also tested separately using the Cuboni reaction, because of the changes in E1S levels during these phases described by Volkery et al. (2012).

In samples from non-pregnant females, the influence of the season on the results of both tests was analysed. The research period was divided into four seasons - spring (March, April, May), summer (June, July, August), autumn (September, October, November) and winter (December, January, February) (Barnett and Dobson 2010). When the influence of seasons was not proved, data were assessed together. When results were influenced by season, data were evaluated separately for each season. 
Data were statistically evaluated in the Statistica $\mathrm{Cz} 12$ program (StatSoft, Inc., 2013). For all calculations, a significance level of $\alpha=0.05$ was established. All calculated numerical values were rounded off to two decimal places. To analyse the data, Pearson's chi-squared test was used.

\section{Results}

In total, we collected 114 urine samples from pregnant $(n=31)$ and non-pregnant $(n=23)$ jennies and from pregnant $(n=29)$ and non-pregnant $(n=31)$ alpaca females. The mean ( \pm SE) length of gestation was $361.36 \pm 3.37$ days in jennies and $338.00 \pm 8.02$ days in alpaca females.

\section{Cuboni reaction}

The results of the Cuboni reaction in non-pregnant jennies were not influenced $(p>0.05)$ by the season. The results of the reaction showed significant differences $(\mathrm{p}<0.01)$ between non-pregnant and pregnant jennies when the pregnancy was considered as a whole period, divided into halves and even thirds (see Tables 1 and 2 for details). In pregnant jennies, $83.87 \%$ of samples were true positives and $16.13 \%$ false negatives. In non-pregnant jennies, $86.96 \%$ were true negatives and $13.04 \%$ false positives.

The results of the Cuboni reaction were also not influenced by the season $(\mathrm{p}>0.05)$ in non-pregnant alpaca females. No relationship was found between the real reproductive status of alpaca females and results of the Cuboni reaction, even if the accuracy was assessed for non-pregnancy versus pregnancy, halves of pregnancy or thirds of pregnancy $(p>0.05)$. The results of the Cuboni reaction in both pregnant and non-pregnant alpaca females were mostly positive (see Table 3). The assessment of pregnancy stages when the first and last months of pregnancy were counted as extra stages was also unsuccessful $(p>0.05)$. However, 3 out of 4 samples from alpacas in the last month of pregnancy showed a positive reaction.

\section{Barium chloride test}

A significant difference was found between the results of the barium chloride test in pregnant and non-pregnant jennies $(\mathrm{p}<0.05)$. Because the season had an influence on the results of the barium chloride test in non-pregnant jennies $(p=0.03)$, the reliability of the barium chloride test was also counted separate- ly for different seasons. In this case, results for pregnant jennies did not significantly differ from results for non-pregnant jennies during spring and autumn $(p>0.05)$. Nevertheless, a difference was found in the summer season $(\mathrm{p}<0.01)$, when the urine of pregnant jennies $(n=12)$ showed a predominantly negative reaction $(91.67 \%)$; conversely, samples from non-pregnant females $(\mathrm{n}=8)$ reacted mainly positively $(87.50 \%)$. When the pregnancy period of jennies was divided into halves and thirds and the results of the barium chloride test in these stages of pregnancy were compared to each other and to the results in non-pregnant jennies, no significant relationship was found between these groups $(\mathrm{p}>0.05)$.

The results of the barium chloride test were not influenced by the season $(\mathrm{p}>0.05)$ in non-pregnant alpaca females. Similarly to the Cuboni reaction, no significant relationship $(\mathrm{p}>0.05)$ was found between the reproductive status of alpaca females and results of the barium chloride test. The majority $(92.86 \%)$ of urine samples showed a negative reaction in alpacas. Just 4 positive reactions (7.14\%) occurred, 2 in pregnant and 2 in non-pregnant alpacas.

\section{Discussion}

The mean lengths of gestation in jennies and alpaca females in our study correspond substantially with other studies (McDonnell 1998, Galisteo and Perez-Marin 2010, Volkery et al. 2012).

The Cuboni reaction seems to be a suitable pregnancy diagnostic test for donkeys. Results in jennies are comparable with results in mares (Cuboni 1934, Hayes 2002, England 2008). These results were expected, because donkeys belong to the same genus, Equus, as horses (Groves and Grubb 2011). The Cuboni reaction could be also tested in other equid species, like zebras or Przewalski's horse, or even in other odd-toed ungulates as a non-invasive method of pregnancy detection. The collection of urine in odd-toed ungulates by the similar method as in presented study was already confirmed by Ramsay et al. (1994). The pregnancy diagnosis in equids is very important for management of captive animals. E.g. the introduction of a stallion, which was not sharing an enclosure with the mare in time close to conception, highly increases the risk of abortion or occurrence of infanticide after parturition in equids (Pluháček and Bartoš 2000, Gray 2009, Bartoš et al. 2011). The pregnancy diagnosis could help to prevent such events.

In comparison with Bactrian camels (Fedorova et al. 2015), the potential of using the test in donkeys is better. Even in camels, the reaction showed $100 \%$ reliability in pregnancy indication during the final third 
of pregnancy (Fedorova et al. 2015); in jennies, the reliability also reached $100 \%$ throughout the whole second half of pregnancy. This corresponds to the fact that Cuboni reaction is based on reaction of oestrogens (Stevenson 1945) and the concentrations of these hormones increase from midpregnancy in jennies (Hoffmann et al. 2014).

Because of this, the Cuboni reaction has the potential to become a standard laboratory method of pregnancy diagnostic in donkeys, similar as in breedings of horses where the rectal palpation or other methods are difficult (Hayes 2002, England 2008). Opposite to that, the Cuboni reaction does not seem applicable in alpacas. Similar results with many false-positive and false-negative reactions were obtained in pigs (Sus scrofa domestica) (Heller 1940) and cattle (O'Moore 1947). The species most closely related to alpacas is the Bactrian camel (Janis et al. 1998), on which the Cuboni reaction was successfully tested (Fedorova et al. 2015). The failure of this method in alpacas should not be caused by a different way of storing and processing of samples or different evaluation of results because the urine samples of Bactrian camels collected by Fedorova et al. (2015) were also stored in the refrigerator before processing and also subjected to the Cuboni reaction at SVI Prague. We can also exclude the possible contamination of urine by soil, because it was caught directly into the cup, however alpacas sometimes defecated during urination and the faeces fell into the cup together with urine. The influence of the animals' management is improbable since animals were kept on three different farms.

False-negative results probably occurred in alpacas because the Cuboni reaction is based on the reaction of free oestrogens in urine (England 2008), and the urinary oestrogen level is highly increased just during the last month of pregnancy in alpacas (Bravo et al. 1996, Volkery et al. 2012). However, in alpacas, the test was not $100 \%$ successful even in the last month of pregnancy when the E1S levels reach a maximum (Bravo et al. 1996, Volkery et al. 2012). This could be caused by the very low number of samples from pregnant females in the last month of pregnancy $(n=4)$ but pregnancy diagnosis during last month of pregnancy dwindles in importance. Besides this, the results in both non-pregnant and pregnant alpacas were mostly positive which suggests that the urinary oestrogen level was sufficient for obtaining positive results even in non-pregnant females. However, blood oestrogen levels of pregnant alpacas are not higher than in donkeys (Aba et al. 1998, Meira et al. 1998) and so no logical explanation of why the Cuboni reaction reaches mostly positive results in alpacas was found. It could be that some unknown component of alpaca urine reacts positively during the Cuboni reaction.

In donkeys, the application of the barium chloride test seems controversial due to the influence of the season. The only significant differences were reached during the summer season but the results showed the opposite trend to other studies, e.g. Ndu et al. (2000a,b) or Lalrintluanga and Dutta (2009). However, similar opposite results have already been presented by Fedorova et al. (2015). Seasonal changes in oestrone levels in non-pregnant females could influence the results of the barium chloride test in jennies. However, according to Galisteo and Perez-Marin (2010), the main reproductive season of donkeys takes place in spring, when the majority of total foal-heat pregnancies were reported, not in summer when we reached only significant differences between pregnant and non-pregnant jennies by the barium chloride test. Besides this, the jennies included in the study gave birth throughout the year so we can cast doubt upon the influence of the season as in the study of Contri et al. (2014). Moreover, urinary oestrone conjugate levels of non-pregnant horse mares in heat never reach the levels in pregnant mares (Daels et al. 1991), and the general hormonal profiles of jennies are similar (Meira et al. 1998).

It was concluded that the barium chloride test is not a suitable pregnancy diagnostic test in alpacas, similar to recent findings for cattle (Krishna Rao and Veena 2009) and Bactrian camels (Fedorova et al. 2015). The urine of alpaca females almost always coagulated after addition of $1 \% \mathrm{BaCl}_{2}$ solution. In contrast, there have been successful experiments in pigs (Ndu et al. 2000a,b, Lalrintluanga and Dutta 2009) and Arabian camels (Banerjee 1974, Purohit 2010).

We tend to agree with the conclusion of Ndu et al. (2000a,b) that differences in results between pregnant and non-pregnant females are probably not caused by progesterone (P4) and pregnanediol-3-glucuronide (PdG). Average differences in $\mathrm{P} 4$ urinary levels in non-pregnant and pregnant alpaca females are high (Volkery et al. 2012) and thus no difference between results of the barium chloride test in pregnant and non-pregnant female alpacas indicates that neither P4 nor PdG are factors preventing or inducing precipitation.

Nevertheless, we must admit that oestrogens do not seem likely to be preventing or inducing factors of precipitation even in jennies. If we know that total blood oestrone reaches maximal levels during midpregnancy and maintains this level until two weeks before parturition (Hoffmann et al. 2014), we would expect that the test would work during the second half or at least the final third of pregnancy in jennies. Nevertheless, testing of the reliability for halves and 
thirds of pregnancy was not successful. In conclusion, oestrogens are probably not preventing or inducing factors of precipitation in the barium chloride test. This statement can also be supported by the fact that we reached different results in the Cuboni reaction which is demonstrably based on reaction of oestrogens (Stevenson 1945).

It is not certain what causes the precipitation of alpaca urine. An increased number of crystals was observed in alpaca urine samples after refrigeration. This was also described in the urine of cats and dogs by Albasan et al. (2003), who found that an increased number and size of crystals was caused by refrigeration, and the number of crystals was higher the longer the refrigeration time. These crystals could be the factor which caused the precipitation of almost all urine samples in alpacas, because urine was not filtrated before barium chloride test processing. Even though the filtration of urine before barium chloride test processing was not described by any author that was cited in this paper, they usually tested freshly collected urine (Ndu et al. 2000a,b, Krishna Rao and Veena 2009, Lalrintluanga and Dutta 2009). Due to the lack of information about factors that influence test results, there is also a lack of information about how urine should be properly preserved for this test. However, the samples of donkey urine were preserved in the same way and the precipitation of urine did not occur so often even though the samples were not filtrated either.

The unreliable results of barium chloride test can be affected also by different content of analytes in urine of studied species. Chemical composition of urine can be different across species. Although camelids and bovids are both ruminants, the anatomy and physiology of digestive tract is different in some aspects (Fowler 2010). Moreover diet and feeding management also affects the composition of urine (Tamminga 1992, Hu and Murphy 2004). According to Maslov and Smirnov (1965), high accuracy of barium chloride test was obtained just in cows kept in cow houses. Animals on pasture, as in our study, could have higher urine oestrogen level due to presence of phytoestrogens in the pasture (Maslov and Smirnov 1965).

In conclusion, the Cuboni reaction seems applicable for pregnancy diagnosis in jennies. The Cuboni reaction has many advantages: (i) collection of urine can be done by breeders themselves, (ii) the reaction can be carried out by accredited laboratories and (iii) the price is acceptable. Because of this, the Cuboni reaction has the potential to become a standard pregnancy diagnostic method in donkeys. In contrast, neither the Cuboni reaction nor the barium chloride test were confirmed as suitable pregnancy diagnostic methods for alpacas, and a search for other simple non-invasive methods for pregnancy diagnosis in alpacas is needed.

\section{Acknowledgments}

We would like to express our special thanks to the breeders for their cooperation. We also thank the Internal Grant Agency of the Faculty of Tropical AgriSciences CULS Prague 2013 (project no. 51120/1312/3112) and CULS Prague University Internal Grant Agency (project no. 20145009) for funding this research.

\section{References}

Aba MA, Sumar J, Kindahl H, Forsberg M, Edqvist LE (1998) Plasma concentrations of 15-ketodihydro-PGF $2 \alpha$, progesterone, oestrone sulphate, oestradiol-17 $\beta$ and cortisol during late gestation, parturition and the early post partum period in llamas and alpacas. Anim Reprod Sci 50: 111-121.

Albasan H, Lulich JP, Osborne CA, Lekcharoensuk C, Ulrich LK, Carpenter KA (2003) Effects of storage time and temperature on $\mathrm{pH}$, specific gravity, and crystal formation in urine samples from dogs and cats. J Am Vet Med Assoc 222: 176-179.

Anderson DE, Jones ML, Miesner MD (2013) Veterinary techniques for llamas and alpacas, 1st ed., John Wiley \& Sons, Ames.

Banerjee S (1974) Comparative efficiency of different diagnostic techniques for pregnancy in camels (Camelus dromedarius) (MVS Thesis), University of Udaipur, Rajasthan, India.

Barnett AG, Dobson AJ (2010) Analysing seasonal health data, 1st ed., Springer-Verlag, Heidelberg.

Bartos L, Bartosovh J, Pluhhcek J, Sindelhrovh J (2011) Promiscuous behaviour disrupts pregnancy block in domestic horse mares. Behav Ecol Sociobiol 65: 1567-1572.

Bello A, Onyeanusi BI, Sonfada ML, Adeyanju JB, Umaru MA, Onu JE (2014) Gross embryonic diffrentiation of the stomach of the one humped camel (Camelus dromedarius). Anat Physiol 4: 131-134.

Blanchard TL, Taylor TS, Love CL (1999) Estrous cycle characteristics and response to estrus synchronization in mammoth asses (Equus asinus americanus). Theriogenology 52: 827-834.

Bravo PW, Stabenfeldt GH, Lasley BL, Fowler ME (1991) The effect of ovarian follicle size on pituitary and ovarian responses to copulation in domesticated South American camelids. Biol Reprod 45: 553-559.

Bravo PW, Stewart DR, Lasley BL, Fowler ME (1996) Hormonal indicators of pregnancy in llamas and alpacas. J Am Vet Med Assoc 208: 2027-2030.

Contri A, Robbe D, Gloria A, De Amicis I, Veronesi MC, Carluccio A (2014) Effect of the season on some aspects of the estrous cycle in Martina Franca donkey. Theriogenology 81: 657-661.

Cote E (2014) Clinical veterinary advisor: dogs and cats, 3rd ed., Mosby, Elsevier, St. Louis, Missouri.

Crisci A, Rota A, Panzani D, Sgorbini M, Ousey JC, Camillo F (2014) Clinical, ultrasonographic, and endocrinological studies on donkey pregnancy. Theriogenology 81: 275-283.

Cuboni E (1934) A rapid pregnancy diagnosis test for mares. Clinical Veterinarian (Milano) 57: 85-93. 
Daels PF, Ammon DC, Stabenfeldt GH, Liu IKM, Hughes JP, Lasley BL (1991) Urinary and plasma estrogen conjugates, estradiol and estrone concentrations in nonpregnant and early pregnant mares. Theriogenology 35: 1001-1017.

El-Ghannam F, El-Azab EA, El-Sawaf S (1974) Preliminary study on the application of Cuboni test for pregnancy diagnosis in the camel. Zuchthygiene 9: 46.

England G (2008) Fertility and obstetrics in the horse, 3rd ed., John Wiley \& Sons, New York.

FAO (2015) FAOSTAT database on agriculture, Food and Agriculture Organization of the United Nations, Rome.

Fedorova T, Brandlovh K, Lukesovh D (2015) Application of noninvasive pregnancy diagnosis in Bactrian camels (Camelus bactrianus) using Cuboni reaction and barium chloride test. J Zoo Wildl Med 46: 355-358.

Fernández-Baca S (1993) Manipulation of reproductive functions in male and female New World camelids. Anim Reprod Sci 33: 307-323.

Fowler ME (2010) Medicine and surgery of camelids, 3rd ed., John Wiley \& Sons, Ames.

Galisteo J, Perez-Marin CC (2010) Factors affecting gestation length and estrus cycle characteristics in Spanish donkey breeds reared in southern Spain. Theriogenology 74: 443-450.

Gauly M, Bourke D (1997) Pregnancy in New World camelids. Dtsch Tierarztl Wochenschr 104: 15-17.

Gray ME (2009) An infanticide attempt by a free-roaming feral stallion (Equus caballus). Biol Lett 5: 23-25.

Groves C, Grubb P (2011) Ungulate taxonomy, Johns Hopkins University Press, Baltimore.

Hayes MH (2002) Veterinary notes for horse owners, 18th ed., Simon and Schuster, New York.

Heller H (1940) Experiments with the Cuboni test for pregnancy diagnosis in the pig ( $\mathrm{PhD}$ thesis), Universitat Wien, Wien.

Hodges K, Brown J, Heistermann M (2010) Endocrine monitoring of reproduction and stress. In: Kleiman DG, Thompson KV, Baer CK (ed) Wild mammals in captivity: principles and techniques for zoo management. University of Chicago Press, Chicago, pp 447-468.

Hoffmann B, Bernhardt AW, Failing K, Schuler G (2014) Profiles of estrone, estrone sulfate and progesterone in donkey (Equus asinus) mares during pregnancy. Tierarztl Prax Ausg G Grosstiere Nutztiere 42: 32-39.

$\mathrm{Hu}$ W, Murphy MR (2004) Dietary cation-anion difference effects on performance and acid-base status of lactating dairy cows: a meta-analysis. J Dairy Sci 87: 2222-2229.

Janis CM, Scott KM, Jacobs LL (1998) Evolution of tertiary mammals of North America: Volume 1, terrestrial carnivores, ungulates, and ungulate like mammals, Cambridge University Press, Cambridge.

Krishna Rao SV, Veena T (2009) Comparison of seed germination test with urine barium chloride test and milk copper sulphate test for efficacy to detect pregnancy in cows. Indian J Anim Res 43: 124-126.

Lalrintluanga K, Dutta M (2009) Pregnancy diagnosis in swine from urine using barium chloride test. Indian J Anim Res 43: 114-116.

Maslov N, Smirnov A (1965) The simplest method for the early diagnosis of pregnancy. Mol Mjasn Skotovod 10: 24-25.

McDonnell SM (1998) Reproductive behavior of donkeys (Equus asinus). Appl Anim Behav Sci 60: 277-282.

Meira C, Ferreira JCP, Papa FO, Henry M (1998) Ovarian activity and plasma concentrations of progesterone and estradiol during pregnancy in jennies. Theriogenology 49: 1465-1473.

Ndu A, Bratte L, Chiboka O (2000a) A preliminary trial on the use of barium chloride for pregnancy diagnosis in pigs. Niger J Anim Prod 27: 9-11.

Ndu A, Bratte L, Eyoufe S (2000b) A preliminary trial on the use of barium chloride for pregnancy diagnosis in sows. Tropicultura 18: 161-163.

O'Moore LB (1947) Sex hormones in the urine of pregnant cattle. J Comp Pathol Ther 57: 36-46.

Pluháček J, Bartoš L (2000) Male infanticide in captive plains zebra, Equus burchelli. Anim Behav 59: 689-694.

Purohit G (2010) Methods of pregnancy diagnosis in domestic animals: the current status. WebmedCentral Reproduction 1: WMC001305.

Ramsay EC, Moran F, Roser JF, Lasley BL (1994) Urinary steroid evaluations to monitor ovarian function in exotic ungulates: X. Pregnancy diagnosis in Perissodactyla. Zoo Biol 13: 129-147.

Rizk BRMB (2010) Ultrasonography in reproductive medicine and infertility, Cambridge University Press, New York.

Rota A, Panzani D, Sabatin C, Camillo F (2012) Donkey jack (Equus asinus) semen cryopreservation: studies of seminal parameters, post breeding inflammatory response, and fertility in donkey jennies. Theriogenology 78: 1846-1854.

Simersky R, Swaczynova J, Morris DA, Franek M, Strnad M (2007) Development of an ELISA-based kit for the on-farm determination of progesterone in milk. Vet Med-Czech 52: 19-28.

Stevenson WG (1945) Pregnant mares' urine as a source of oestrogens. Can J Comp Med Vet Sci 9: 293-301.

Sumar JB (1999) Reproduction in female South American domestic camelids. J Reprod Fertil Suppl 54: 169-178.

Tamminga S (1992) Nutrition management of dairy cows as a contribution to pollution control. J Dairy Sci 75: 345-357.

Thomas P, Asa CS, Hutchins M (2010) The management of pregnancy and parturition in captive mammals. In: Kleiman DG, Thompson KV, Baer CK (eds) Wild mammals in captivity: principles and techniques for zoo management. University of Chicago Press, Chicago, pp 344-366.

Volkery J, Wittek T, Sobiraj A, Gottschalk J, Einspanier A (2010) Progesterone and pregnanediol-glucuronid concentrations in saliva, milk and urine of female alpacas and their application in pregnancy diagnosis. Berl Munch Tierarztl Wochenschr 123: 500-505.

Volkery J, Gottschalk J, Sobiraj A, Wittek T, Einspanier A (2012) Progesterone, pregnanediol-3-glucuronide, relaxin and oestrone sulphate concentrations in saliva, milk and urine of female alpacas (Vicugna pacos) and their application in pregnancy diagnosis. Vet Rec 171: 195-195.

Waits LP, Paetkau D (2005) Noninvasive genetic sampling tools for wildlife biologists: a review of applications and recommendations for accurate data collection. J Wildl Manage 69: 1419-1433.

Webster J (2011) Management and welfare of farm animals: the UFAW farm handbook, 5th ed., John Wiley \& Sons, Chichester.

You R, Lv L, Cheng Z, He J, Smith GW, Dong C (2013) Application of ultrasonography for early pregnancy diagnosis in alpacas (Lama pacos). J Anim Vet Adv 12: $539-543$. 